
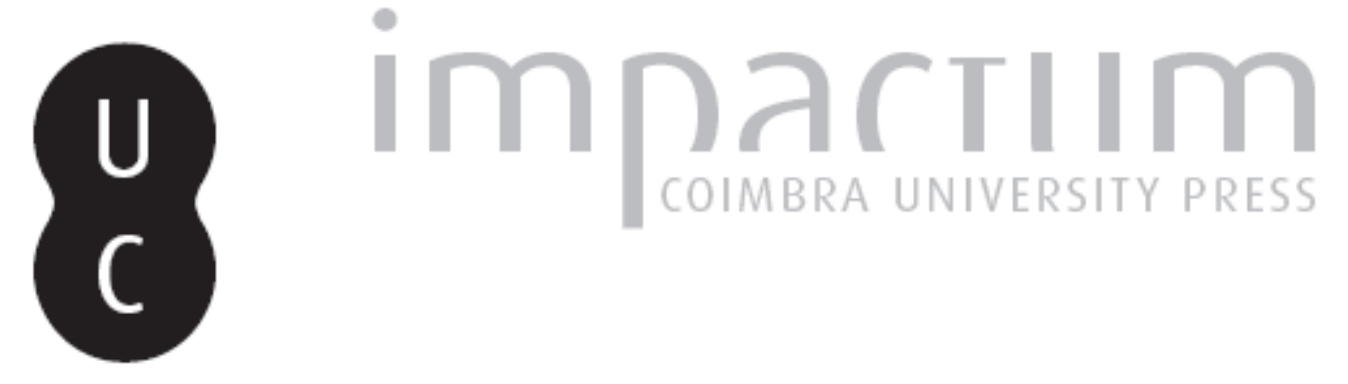

\title{
A definição de alegoria segundo os gramáticos e rétores gregos e latinos
}

Autor(es): Martinho, Marcos

Publicado por: Sociedade Brasileira de Estudos Clássicos

URL persistente:

URI:http://hdl.handle.net/10316.2/35760

DOI:

DOI:http://dx.doi.org/10.14195/2176-6436_21-2_6

Accessed : $\quad$ 26-Apr-2023 11:07:04

A navegação consulta e descarregamento dos títulos inseridos nas Bibliotecas Digitais UC Digitalis, UC Pombalina e UC Impactum, pressupõem a aceitação plena e sem reservas dos Termos e Condições de Uso destas Bibliotecas Digitais, disponíveis em https://digitalis.uc.pt/pt-pt/termos.

Conforme exposto nos referidos Termos e Condições de Uso, o descarregamento de títulos de acesso restrito requer uma licença válida de autorização devendo o utilizador aceder ao(s) documento(s) a partir de um endereço de IP da instituição detentora da supramencionada licença.

Ao utilizador é apenas permitido o descarregamento para uso pessoal, pelo que o emprego do(s) título(s) descarregado(s) para outro fim, designadamente comercial, carece de autorização do respetivo autor ou editor da obra.

Na medida em que todas as obras da UC Digitalis se encontram protegidas pelo Código do Direito de Autor e Direitos Conexos e demais legislação aplicável, toda a cópia, parcial ou total, deste documento, nos casos em que é legalmente admitida, deverá conter ou fazer-se acompanhar por este aviso.

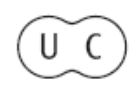




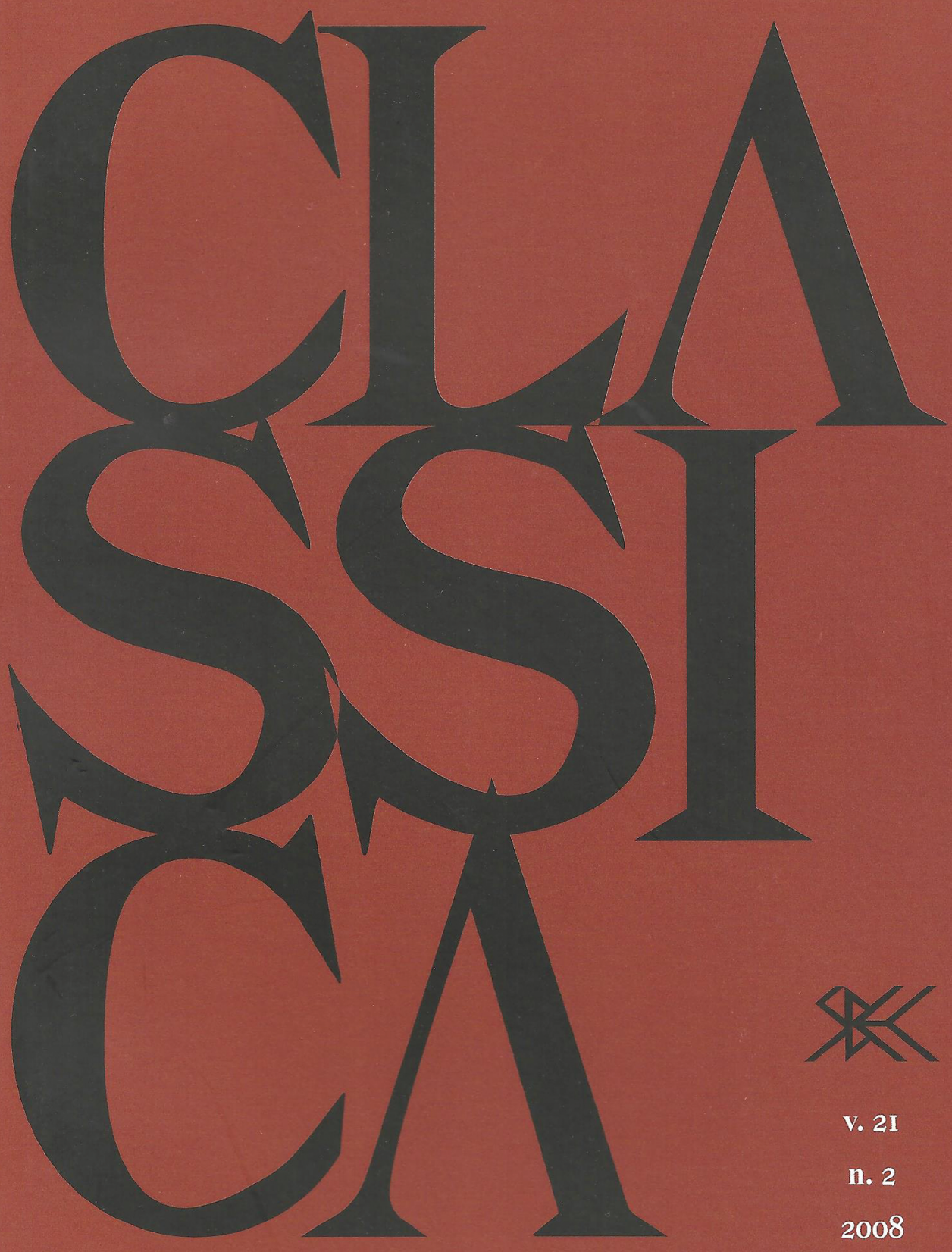




\title{
A definição de alegoria segundo os gramáticos e rétores gregos e latinos
}

\author{
Marcos Martinho \\ Universidade de São Paulo \\ Brasil
}

\begin{abstract}
Resumo. A definição de alegoria que predomina nos gramáticos e rétores gregos e latinos é aquela segundo a qual alegoria diz uma coisa e entende outra. Assim, investigo, em primeiro lugar, os gramáticos e rétores que se detêm, por exemplo, a discernir o que se diz e o que se entende, ou a explicar como a alegoria opera ao nível da dicção, isto é, das palavras, e como opera ao nível da intelecção, isto é, dos casos. Já a descrição, rara nos gramáticos e rétores, segundo a qual alegoria transfere palavras do caso próprio para o outro caso, muito se aproxima à descrição de metáfora. Assim, investigo, em segundo lugar, os gramáticos e rétores que ensinam, por exemplo, em que a alegoria se distingue da metáfora.
\end{abstract}

Palavras-chave. Alegoria; metáfora; enigma; tropo.

\section{Que é a alegoria e como se faz}

\subsection{Segundo os gramáticos e rétores latinos}

A Retórica a Herênio define permutação como oração que demonstra uma coisa pelas palavras, outra pela sentença. ${ }^{1}$ Ora, trata-se de saber, antes de tudo, que é aquilo que mostra com as palavras e que é aquilo que mostra com a sentença; mas a Retórica a Herênio não se pronuncia acerca disso. Quintiliano, ao rememorar a definição da Retórica a Herênio, diz tão-só que a alegoria ostenta uma coisa pelas palavras, outra pelo sentido, ${ }^{2}$ de maneira que também ele não explica o que seja aquilo que se demonstra com as palavras, nem o que seja aquilo que se demonstra com o sentido.

Cícero, porém, após dizer que, por meio daquilo que flui do gênero da translação, uma coisa se diz, outra é para entender, explica, de um lado,

\section{Email: marcos.martinho@usp.br}

Faculdade de Filosofia, Letras e Ciências Humanas.

${ }^{1}$ Rhet. Her. 4.46: Permutatio est oratio aliud uerbis aliud sententia demonstrans.

${ }^{2}$ Quint. 8.6.44: aliud uerbis, aliud sensu ostendit. 
que, então, as palavras próprias de um caso são transferidas a outro caso. ${ }^{3}$ Alegoria, pois, seria o torneio pelo qual se diz o caso a que as palavras são apropriadas e se entende o caso a que as palavras são transferidas; tal seria, pois, o caso que se demonstra pelas palavras, e tal, o caso que se demonstra pela sentença. Mas Cícero não explica, de outro lado, se, ao serem transferidas do caso próprio para o outro, as palavras preservam o caso próprio, de modo que sobreponham este ao outro, ou se desistem do caso próprio, de modo que substituam este pelo outro. Trata-se de saber, pois, se o que se diz são palavras que substituem a referência ao caso próprio pela transferência ao outro caso, de maneira que o que se entenda seja tão-só o outro caso, ou se as palavras acrescentam a transferência à referência, de maneira que o que se entenda sejam os dois casos: o próprio e o outro.

Ora, a definição de Cícero é rememorada por muitos, mas estes, ao fazê-lo, omitem bem a explicação que aquele apõe à descrição de alegoria. Assim, Caio Júlio Vítor define alegoria dizendo que uma coisa se diz, e outra se entende, de maneira que, de um lado, não explica o que seja aquilo que se diz, nem o que seja aquilo que se entende, e, de outro lado, acaba por opor o entender ao dizer. ${ }^{4}$ Assim também, alguns gramáticos opõem o significar ao dizer, ${ }^{5}$ e Mário Plócio Sacerdote opõe ao que se significa o que está contido nas palavras. ${ }^{6}$ Nenhum desses, pois, diz claramente o que seja aquilo que se diz ou está contido nas palavras, nem o que seja aquilo que se entende ou significa. Demais, ao opor isto, que se significa ou entende, àquilo, que está contido nas palavras ou se diz, parecem admitir que a dicção ou palavras não encerram em si nenhum entendimento, nenhuma significação, como se fossem simples som que, ao ser transferido do caso próprio para o outro, troca aquele por este.

${ }^{3}$ Cic. De or. 3.41.166-7: Nam illud, quod ex hoc genere profluit, non est in uno verbo translato, sed ex pluribus continuatis connectitur, ut aliud dicatur, aliud intelligendum sit. [...] Sumpta re simili, verba eius rei propria deinceps in rem aliam, ut dixi, transferuntur. ${ }^{4}$ J. VICT. Ars rhet. 20: RLM p. 432, 1. 16-7: ut aliud dicas et aliud intellegendum sit.

${ }_{5}^{5}$ SACERD. Art. gram.: GL VI p.461, 1. 7-8: aliud significans quam continetur in verbis; Char. Ars gram.: GL I p. 276, 1. 4: aliud dicens aliud significans; Dıм. Ars gram.: GL I p. 461, 1. 31: aliud dicens aliud significans; Don. AM: GL IV p.401, 1. 26: quo aliud significatur quam dicitur; II Vit. uirt. or. 380-1: quae aliud ostendit extrinsecus, aliud significat quam dicitur; BED. De fig. et trop.: RLM p. 615, 1. 31: quo aliud significatur quam dicitur; Мrтнсн. In Don. AM: CCCM XL p. 246, 1. 96-7: quo aliud significatur quam dicitur; SEDUl. In Don. AM: CCCM XLb p.386, 1. 90-1: quo aliud significatur quam dicitur [...] aliud significatur quam dicitur [...] aliud significatur quam dicitur; Cod. Bern. 16.: GL Supl. p. XLVI, 1. 1: quo aliud significatur, quam dicitur; GERV. AP p. 149, 1. 4: aliud significari quam dici; Scem. dian. rhet. p. 154, 1. 54: aliud dicens aliud significans.

${ }^{6}$ SACERD. Art. gram.: GL VI p.461, 1. 7-8: aliud significans quam continetur in verbis.

Classica (Brasil) 21.2, 252-264, 2008 
Ora, para tal opinião parecem pender muitos dos que glosam a definição daqueles gramáticos. Pompeio, por exemplo, explica a oposição de dizer e significar, dizendo que as palavras soam uma coisa, e o caso tem outra, de maneira que não só reduz palavras a som, mas opõe palavras a caso, ${ }^{7}$ e o Comentário de Einsiedeln ao Barbarismo de Donato, ao explicar a mesma oposição, diz que uma coisa soa nas palavras, e outra se entende no sentido, de maneira que não só restringe palavra a som, mas opõe palavra a sentido, ${ }^{8}$ outros, enfim, guardam tão-só a oposição do que soa ao que se entende. ${ }^{9}$ Seja como for, todos parecem admitir que a palavra é um som vazio de sentido, e este, uma intelecção a que a palavra ou é referida propriamente ou é transferida impropriamente, de maneira que a palavra não superpõe o caso próprio ao outro, mas substitui a referência àquele pela transferência a este. Daí, poder-se-ia concluir que tal é mesmo a acepção do lat. permutatio, pelo qual a Retórica a Herênio traduz o gr. allegoría: permutação do caso próprio pelo outro caso, e não sobreposição deste àquele.

A par das definições de alegoria da Retórica a Herênio e Cícero e dos comentários a estes dos gramáticos e rétores sobreditos, são também mais ou menos breves ou concisas as definições dos glossários e glosas redigidos nos séc. VII-VIII d.C.. Ora, de um lado, as Glosas do códice de Saint Gallen 912 (séc. VII d.C.) e o glossário $A B B A$ (séc. VII d.C.?) definem alegoria dizendo que se significa uma coisa em lugar de outra, ${ }^{10}$ e as Glosas do códice de Leiden 67F: affatim (séc. VII d.C.?), dizendo que se significa uma coisa a partir de outra, ${ }^{11}$ de maneira que parecem entender que um significado se substitua a outro, ou ainda, que o caso próprio se permute com o outro. De outro lado, as Glosas do códice de

${ }^{7}$ Poмp. Com. art. Don.: GL V p. 310, 1. 23-4: quotiens aliud dicimus et aliud significamus; verba nostra aliud sonant et res aliud habet.

${ }^{8}$ Com. Einsidl. in Don. barb.: GL Supl. p. 272, 1. 15-7: quo aliud significatur quam dicitur, $i$. quando aliud sonat in uerbis atque aliud in sensu intelligitur; cf. Ars Laur.: CCCM XLa p. 233, 1. 57 - p. 234, 1. 62: quo aliud significatur quam dicitur. Quotiens aliud uerbo dicimus, et sensu aliud significamus [...] dum ergo aliud dicebat et aliud significabat. Assim como esses, que comentam definições de alegoria que dependem da definição de Cícero, assim as Cores de palavras, ao comentar a definição da Retórica a Herênio, restringem a palavra ao som e opõem a palavra à sentença: Permutatio est oratio aliud verbis, aliud sententia demonstrans [...] / Non ibi verba sonant quod ibi sententia clamat (Color. uerb. 59). ${ }^{9}$ IsID. Orig. 1.37.22: aliud enim sonat, et aliud intellegitur; Iulian. Tol. Ars 19.74: quo aliud significatur quam dicitur [...]. aliud enim sonat et aliud intellegitur; I Vit. uirt. or. 613: in quo aliud sonat et aliud intellegitur.

${ }^{10}$ Glos. Sangall. 912: CGL IV p. 206, 1. 1: aliud pro aliod significans; ABBA AL 46: GL V p. 23: aliud pro alio significans.

${ }^{11}$ Glos. Leid. 67F: affatim: CGL IV p. 476, 1. 52: aliud ex aliud significantia. 
Leiden 67F: affatim e o Glossário de Ansileubo (posteriore parte séc. VIII d.C.) abonam outra definição, segundo a qual a alegoria é valor geminado de investigar conhecimento, de modo que uma coisa esteja na voz, outra na ciência. ${ }^{12}$ Ora, é verdade que, assim, opõem a ciência, a que pertenceria o caso, à voz, a que pertenceriam as palavras; porém, chama a atenção que esse arrazoado seja explicação da expressão uis gemina ou valor geminado, porque, se é dupla a valência da alegoria, dois seriam os casos desta, ou ainda, o outro caso se somaria ao caso próprio, e não se permutaria este com aquele. A expressão, aliás, emana de Isidoro de Sevilha e Juliano de Toledo, ${ }^{13}$ que dela se valem para discernir a diferença entre alegoria e enigma, como explico mais abaixo.

Ora, se a compreensão de alegoria de tais gramáticos e rétores ou de tais glosas e glossários é que é imperfeita, ou se a descrição é que é imprecisa, não vem ao caso; o que importa, sim, é que outros, se não foram mais agudos de entendimento, foram mais exatos na enunciação. Assim, Teodorico de Chartres, ao comentar a definição de permutação da Retórica a Herênio, descreve aquela como imposição de palavras em significação própria, pela qual significação, todavia, se faz notar o outro caso. ${ }^{14}$ Assim, vê-se de tal descrição, primeiro, que há, de um lado, a significação própria e, de outro, a notação do caso alheio; depois, que as palavras próprias de um caso, ao fazer notar o outro, não só não perdem o significado próprio, mas por meio deste, sim, é que fazem notar o outro caso. Demais, Teodorico equipara, de um lado, significação e intelecção do caso alheio e refere, de outro, subintelecção do caso alheio. Disso poderia inferir-se, primeiro, que, assim como há duas intelecções, assim também, duas significações e, daí, que a primeira significação é tão-só intelecção, e a segunda significação, subintelecção.

Mateus de Vendôme, por sua vez, define alegoria dizendo que a intelecção dissente da significação das palavras..$^{15}$ Assim, distingue entre significação, que pertenceria ao caso próprio, a que as palavras são referidas, e intelecção, que pertenceria ao outro caso, a que as palavras

${ }^{12}$ Glos. Leid. 67F: affatim: CGL IV p. 477, 1. 1: inuestigande cogitationes uix gemina aut aliud sit inscientia; Glos. Ansil. AL111: GL I p. 44: investigandae cognitionis vis gemina ut aliud sit in voce, aliud in scientia.

${ }^{13}$ IsID. Orig. 1.37.26: quod allegoria vis gemina est; Iulian. Tol. Ars 19.89: quod allegoria uis gemina est.

${ }^{14}$ ThDrc. Com. sup. Rhet. Her. 4.34.46: Permutatio verborum in propria significatione est positio, per quam tamen significationem fit alterius rei notatio.

${ }^{15}$ MAt. VIN. AV 3.43: Amplius, allegoria est alienum eloquium quando a verborum significatione dissidet intellectus. 
são transferidas. Alexandro de Villedieu, enfim, define alegoria dizendo que se designa algo outro que o que a cláusula significa. ${ }^{16}$ Assim, distingue entre o designare ou designação, que pertenceria à referência das palavras ao caso próprio, e o signare ou significação, que pertenceria à transferência das palavras ao outro caso.

Em suma, tais gramáticos e rétores admitem que a alegoria sobreponha a transferência para o outro caso à referência ao caso próprio, e não que permute esta por aquela, ainda que estejam a comentar, como Teodorico de Chartres, a definição de permutatio da Retórica a Herênio.

\subsection{Segundo os gramáticos e rétores gregos}

Suidas diz que existe alegoria quando a escrita fala uma coisa, e a intelecção, outra, ${ }^{17}$ e a Coleção de léxico proveitoso de Fócio, quando a escrita declara uma coisa, e a intelecção compreende outra. ${ }^{18}$ Assim, antes de tudo, não fazem ver o que seja aquilo que a escrita fala ou declara, nem o que seja aquilo que a intelecção compreende; demais, deixam entrever a oposição daquilo que a intelecção compreende àquilo que a escrita fala ou declara. ${ }^{19}$ Trata-se, pois, de saber, de um lado, o que é isso que a alegoria diz pela escrita e o que é isso que compreende pela intelecção e, de outro lado, de averiguar se a escrita, de fato, já não encerra em si alguma intelecção.

Ora, Pseudo-Plutarco diz que a alegoria assenta uma coisa por meio de outra; ${ }^{20}$ Suidas, que alega umas coisas por meio de outras; ${ }^{21}$ João de Sicília, que significa uma coisa por meio de outra. ${ }^{22}$ Esse mesmo torneio, segundo o qual se diz, vagamente, que a alegoria faz uma coisa por meio

\footnotetext{
${ }^{16}$ Alex. V.-D. Doctr. 2541-2: cum designatur aliud quam clausula signat, / allegoria datur.

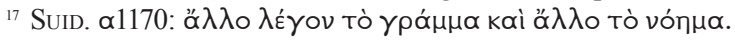

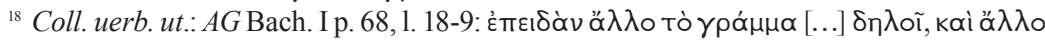

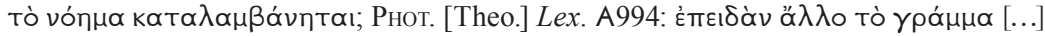

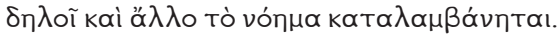

${ }^{19} \mathrm{Na}$ mesma obscuridade incorreriam os que definem alegoria etimologicamente, de modo a dizer que a palavra allegoría deriva de alegar-se (cf. agoreúein) outro (cf. állo) que o suposto, isto é, que a alegoria alega alguma intelecção diferente do suposto,

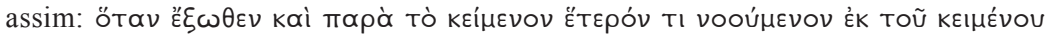

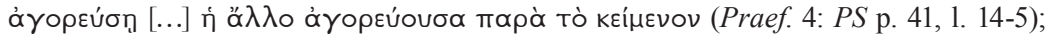

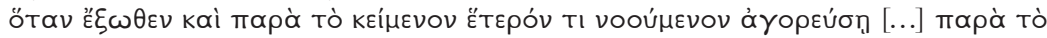

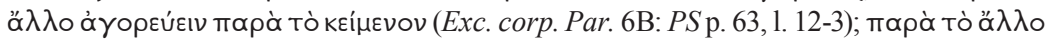

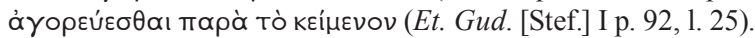

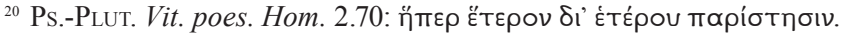

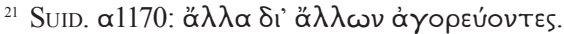

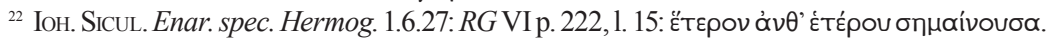


de outra, é empregado, já com maior precisão, pelo mesmo João de Sicília e por outros. Assim, Pseudo-Demétrio, de um lado, diz que a alegoria significa um caso por meio de outro caso, ${ }^{23}$ e João de Sicília, de outro lado, que a alegoria enigmatiza uma intelecção por meio de outras. ${ }^{24}$ Daí, poder-se-ia concluir, primeiro, que aquilo que a alegoria diz pela escrita é um caso, e aquilo que compreende pela intelecção, outro caso; depois, que há duas intelecções, e não uma, a saber: a do caso dito e a do caso compreendido. Porém, nem Pseudo-Demétrio discerne quais são um e outro caso, nem João de Sicília explica como se fazem uma e outra intelecção.

Ora, de um lado, Gregório de Corinto, o Acerca dos tropos poéticos e os escólios de Londres da Arte de Dionísio da Trácia definem alegoria como frase que diz uma coisa e assenta intelecção de outra, ${ }^{25}$ George Querobosco, como palavra que fala uma coisa e assenta outra intelecção; ${ }^{26}$ Trifão, como arrazoado que declara propriamente uma coisa, mas assenta intelecção de outra: ${ }^{27}$ Cocôndrio, como frase que declara uma coisa propriamente, mas assenta outra intelecção. ${ }^{28} \mathrm{Bem}$ que essas lições pareçam depender umas das outras, a definição de Cocôndrio é a mais exata, por isto de admitir, como George Querobosco, e discernir, como Trifão, duas intelecções. De fato, ao dizer, de um lado, que a alegoria declara propriamente uma coisa, discerne o que pertence à declaração, isto é, o caso próprio, e, ao dizer, de outro lado, que a alegoria assenta, não intelecção de outra coisa, mas outra intelecção, admite que já a declaração ponha, primeiro, a intelecção própria, à qual se sobreporia, depois, a outra intelecção. De outro lado, Tibério o Rétor diz que existe alegoria quando se codifica algo de próprio em metáforas ou transferências capacitadas a significar o próprio. ${ }^{29}$ Assim, entende,

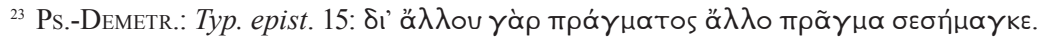

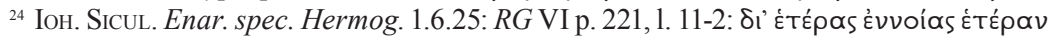

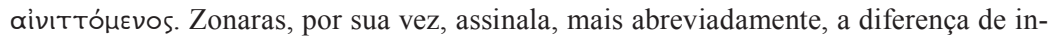

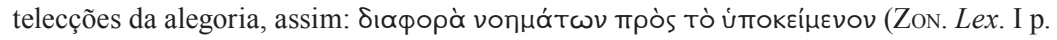
125, 1. 8-10).

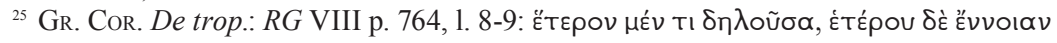

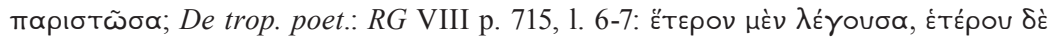

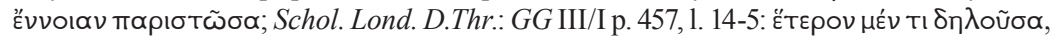

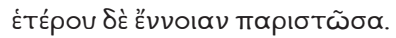

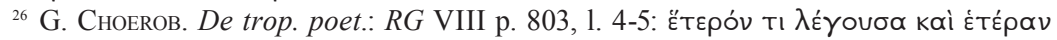

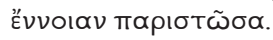

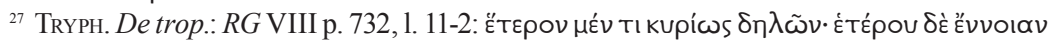
тарібтর́ $v \omega v$.

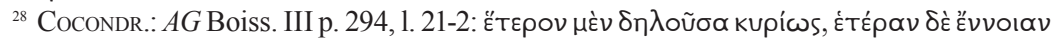

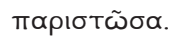

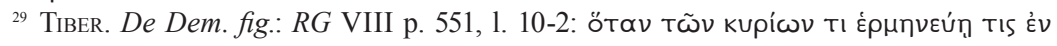


primeiro, que, de um lado, está a codificação e, de outro, a significação; depois, que a transferência que codifica o próprio é capaz de significá-lo, ou seja, que as palavras transferidas ou metafóricas, ao codificar o próprio, continuam a significá-lo, de maneira que a codificação se sobrepõe, sem substituí-la, à significação.

A par desses, Hesíquio diz que a alegoria indica, sob o que se ouve, algo outro que este, ${ }^{30}$ e Zonaras, que indica, sob o que se entrevê, algo outro que este. ${ }^{31}$ Ora, ainda que não digam o que seja aquilo que se ouve ou entrevê, nem o que seja aquilo que se indica, admitem que haja sobreposição de uma coisa à outra, e não permutação. Demais, ainda que Hesíquio fale no que se ouve, e Zonaras, no que se entrevê, admite-se que a alegoria, porque transfere palavras, depende do que se ouve, e, porque superpõe casos, depende do que se entrevê. De acordo com o segundo arrazoado, aliás, é que Pseudo-Demétrio diria que a alegoria, para fazer ver um caso, sinaliza a imagem de outro. ${ }^{32}$

Logo, de tais definições poder-se-ia concluir, primeiro, que o caso que a alegoria declara é o próprio à escrita, e o que compreende, caso alheio a esta; depois, que a intelecção do caso próprio se faz pela significação da declaração, ou melhor, pela referência das palavras àquele caso, e a intelecção do caso alheio, pela codificação da declaração, ou melhor, pela transferência das palavras àquele; enfim, que a intelecção do caso alheio se sobrepõe à do caso próprio, ou ainda, que a codificação se soma à significação. Avessa a tais definições, porém, é a de Longino, que diz que a alegoria consiste em transladar um nome e, por meio de nome mais novo, significar o mesmo caso. ${ }^{33}$ De fato, ao passo que os outros gramáticos e rétores descrevem a alegoria como transferência de palavra do caso próprio ao caso alheio, Longino descreve a alegoria como substituição de uma palavra por outra mais nova para significar o mesmo caso. Ora, se aqueles gramáticos e rétores atentam no que a alegoria opera ao nível dos casos, Longino atenta no que a alegoria opera

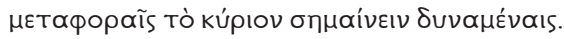

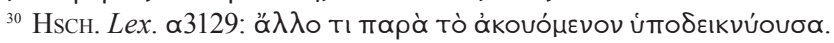

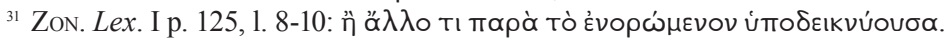

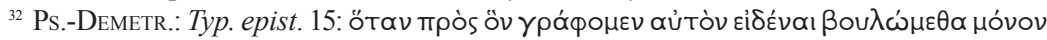

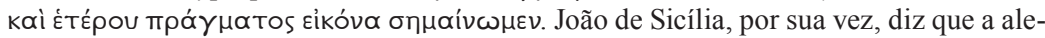
goria não faz aparecer o que quer, mas, encobrindo o aparente, indica outra coisa, assim:

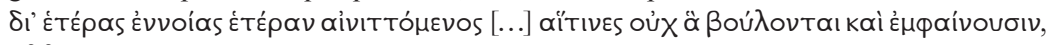

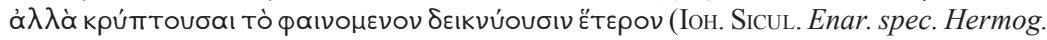
1.6.25: $R G$ VI p. 221, 1. 11-2. 28-30).

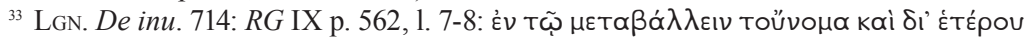

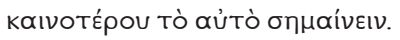


ao nível das palavras. Assim, segundo aqueles, uma mesma palavra pode referir-se ao caso próprio ou transferir-se a caso alheio; segundo Longino, um mesmo caso pode ser significado pela palavra habitual ou por outra mais nova. Daí, de um lado, a palavra, ao ser transferida a caso alheio, superpõe este ao caso próprio; de outro lado, o caso, ao ser significado por palavra mais nova, substitui por esta a palavra habitual. Em suma, a alegoria opera, ao nível dos casos, a adição ou superposição destes e, ao nível das palavras, a substituição ou permutação destas.

\section{A alegoria segundo o gênero e a espécie}

\subsection{O gênero da metáfora}

Ora, a alegoria, ao nível das palavras, opera a permutação da palavra habitual e comum com outra mais nova, segundo Longino, ou das palavras próprias com as rebuscadas, segundo Quintiliano. ${ }^{34} \mathrm{O}$ mais dos gramáticos e rétores, porém, atenta no que a alegoria opera ao nível dos casos, de modo que digam que a alegoria transfere a palavra ${ }^{35}$ do caso próprio para o outro caso. ${ }^{36}$ Tal descrição, porém, coincide com a descrição de metáfora ou translação, como se vê, por exemplo, do cotejo das descri-

${ }^{34}$ QuINT. 8.6.47: propriis [...] uerbis; 48: [...] ex arcessitis uerbis [...] ex propriis.

${ }^{35}$ Dos que referem a transferência da palavra rememorem-se estes: Retórica a Herênio (cf. Rhet. Her. 4.46: translationes; ib.: per translationem), Cícero (cf. Cic. De or. 3.41.166: translato; Or. 27.94: tralationes), Quintiliano (cf. Quint. 8.6.44: tralationibus, 49: tra-

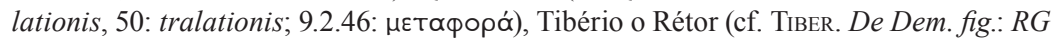

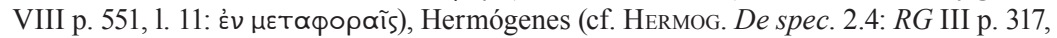

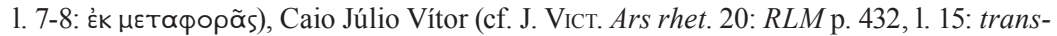
latio), Marciano Capela (cf. CAPEL. V 512: p. 177, 1. 7: transferendi), Murethach de Irlanda (cf. Мrтнсн. In Don. AM: CCCM XL p. 246, 1. 99: translata), Suidas (cf. SuID. $\alpha 1170$ :

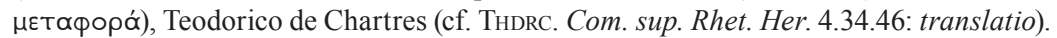
${ }^{36}$ Dos que discernem o caso próprio e o caso alheio rememorem-se estes: Cícero (Cic. De or. 3.41.167: Sumpta re simili, verba eius rei propria deinceps in rem aliam, ut dixi, trans-

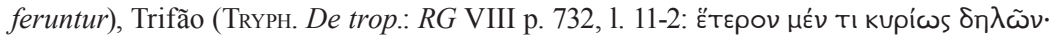

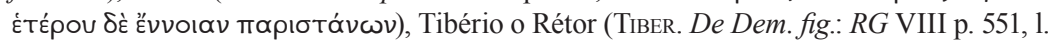

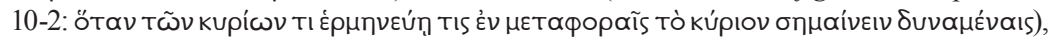
George Querobosco (G. ChOEROB. De trop. poet.: RG VIII p. 804, 1. 6: kupíws), Murethach de Irlanda (Мrтнсн. In Don. AM: CCCM XL p. 246, 1. 98-9.2: Propria dictio est [...]; translata dictio est [...]; similitudo non propria), Gregório de Corinto (GR. CoR. De trop.: RG VIII p. 765, 1. 3: kupíws), Teodorico de Chartres (ThDrc. Com. sup. Rhet. Her. 4.34.46: Permutatio verborum in propria significatione est positio, per quam tamen significationem fit alterius

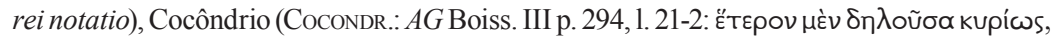

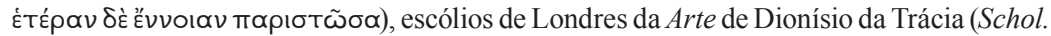
Lond. D.Thr.: GG III/I p. 457, 1. 19: kupíws). 
ções de alegoria e metáfora propostas por Cícero. De fato, compare-se esta descrição de alegoria:

Sumpta re simili, verba eius rei propria deinceps in rem aliam, ut dixi, transferuntur (CIc. De or. 3.41.167)

Tomado um caso semelhante, as palavras próprias desse caso, como disse, são transferidas depois a outro caso,

com esta outra, de metáfora:

Tralata ea dico, ut saepe iam, quae per similitudinem ab alia re [...] transferuntur (CIC. Or. 27.92)

Translatas digo, como já amiúde, aquelas [palavras] que são transferidas [...] de outro caso por meio de semelhança.

Na verdade, Cícero entende que a alegoria pertence ao gênero da translação (cf. id. De or. 3.41.166: quod ex hoc genere profluit; CAPEL. V 512: p. 177, 1. 7: in hoc genere transferendi), de maneira que chega mesmo a ponderar que o gr. allegoría é correto pelo nome, mas que, pelo gênero, seria melhor dizer tão-só translação ou transferência; ${ }^{37}$ já Suidas simplesmente equipara allegoría e metaphorá. ${ }^{38}$ Daí, poder-se-ia dizer que o gr. metaphérein e o lat. transferre são usados na descrição de metáfora, mas são usurpados na descrição de alegoria, de maneira que lá se empreguem propriamente, mas aqui, metaforicamente ou, se se preferir, por catacrese. Logo, trata-se de saber em que a transferência alegórica difere da transferência metafórica, ou ainda, o que tem aquela de específico, já que esta é genérica.

Ora, o mesmo Cícero explica que a alegoria, que flui do gênero da translação, não está na translação de uma única palavra, mas da continuação de várias se entrelaça, ${ }^{39}$ ou ainda, que a alegoria se faz quando várias translações contínuas se implicaram. ${ }^{40}$ No entanto, tal descrição, bem que importe para distinguir alegoria de metáfora, é rara nos gramáticos e rétores latinos e é mesmo ausente dos gregos. Na verdade, pode-se

${ }^{37}$ Cic. Or. 27.94: Itaque genus hoc Graeci appellant $\alpha \dot{\alpha} \lambda \lambda \eta \gamma$ píav, nomine recte, genere melius ille, qui ista omnia tralationes vocat.

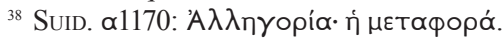

${ }^{39}$ Cic. De or. 3.41.166: Nam illud, quod ex hoc genere profluit, non est in uno verbo translato, sed ex pluribus continuatis connectitur.

${ }^{40}$ Cic. Or. 27.94: Iam cum flexerunt continuae plures tralationes, alia plane fit oratio. 
dizer que, além de Cícero, só a Retórica a Herênio a abona, ao dizer que a permutação se faz quando se dispõem translações mais frequentes, ${ }^{41} \mathrm{e}$ que os outros poucos gramáticos e rétores que a recorrem só fazem rememorar as lições desta e daquele, e nunca a explicam, nunca a alargam. Assim, dos que celebram as palavras de Cícero, Caio Júlio Vítor apenas as transcreve, ${ }^{42}$ e Marciano Capela, ao dizer que os poetas enlaçam a alegoria (cf. CAPEL. V 512: p. 177, 1. 8: nexuerunt), ${ }^{43}$ parece aludir ao dizer de Cícero, segundo o qual a alegoria se entrelaça da continuação de várias translações (cf. Cic. De or. 3.41.166: connectitur). Dos que dependem da Retórica a Herênio, Quintiliano rememora-a, ao dizer que o uso contínuo da metáfora faz a alegoria, ${ }^{44}$ e Teodorico de Chartres comenta-a, ao explicar que a permutação se faz quando mais de um se compara a mais de um, e glosa-a, ao interpretar consequenter por meio de continue. ${ }^{45}$

Ora, é a essa descrição que Cícero prende a definição de alegoria como torneio pelo qual se entende, pela dicção, o caso próprio, e se subentende, pela intelecção, o outro caso. Assim, porém, parece admitir que a intelecção pertence, não à palavra, mas a toda a oração, ou melhor, que o caso não se depreende das partes da oração, mas se compreende no todo. Por isso, de um lado, a metáfora não chega a alhear a intelecção, porque se confina numa única palavra, e, daí, a oração conserva o caso próprio; por isso, de outro lado, a alegoria altera a intelecção, porque torce a oração toda, e, daí, esta envereda para outro caso. Daí viria, aliás, um reparo de Quintiliano. Pois, ao ilustrar, com dois passos de Cícero, o uso da alegoria inteira, ou melhor, da alegoria que preenche toda a oração, e o uso da alegoria misturada a palavras abertas, ou melhor, da alegoria que se confina em parte de oração, Quintiliano observa que, por faltar a transferência a uma única parte da oração, já não se pode mesmo dizer que haja alegoria. Assim, acerca deste passo do Por Milão:

$\mathrm{Sim}$, as mais tempestades e procelas, ao menos naqueles refluxos dos comícios, sempre pensei que eram para Milão suportar (Cic. Mil. 2.5),

\footnotetext{
${ }^{41}$ Rhet. Her. 4.46: cum translationes plures frequenter ponuntur.

${ }_{42}$ J. VicT. Ars rhet. 20: RLM p. 432, 1. 15-6: Est translatio non in uno verbo, sed in pluribus continuatis.

${ }^{43}$ CAPEL. V 512: p. 177, 1. 7-8: in hoc genere transferendi etiam allegoriam poetae praecipue nexuerunt.

${ }^{44}$ Quint. 8.6.14: continuus uero in allegorian [...] exit; 8.6.44: continuatis tralationibus;

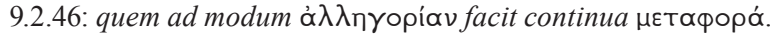

${ }^{45}$ Thdrc. Com. sup. Rhet. Her. 4.34.46: quando plura pluribus comparantur; ib.: consequenter id est continue.
} 
Quintiliano observa que, porque se adicionou "ao menos naqueles refluxos dos comícios", não é alegoria (Quint. 8.6.47-8). De fato, "dos comícios" é expressão aberta, e basta que essa parte da oração não seja transferida ao outro caso, isto é, à náutica, para que a oração toda ressalve o caso próprio, isto é, a política.

\subsection{A espécie do enigma}

A par da lição supracitada, diz Cícero que, assim como da continuação da metáfora nasce a alegoria, assim da continuação desta nasce o enigma. ${ }^{46}$ Esta outra lição, também rara nos gramáticos e rétores, é rememorada por dois latinos e antecipada por um grego. Assim, recorrem-na Quintiliano, que diz que o uso contínuo da metáfora dá em alegoria e, daí, em enigma, ${ }^{47}$ e Caio Júlio Vítor, que transcreve as palavras de Cícero, ${ }^{48}$ antecipa-se a este, porém, Demétrio, que nos aconselha a vigiar sobre o uso contínuo da alegoria, para que o arrazoado não nos engendre enigma. ${ }^{49}$ Demais, assim como diz que a alegoria flui do gênero da metáfora, assim diz Cícero que é no gênero da alegoria que se fazem os assim chamados enigmas. Essa lição, porém, é frequente nos gramáticos e rétores, que, na verdade, consignam à alegoria não só a espécie do enigma, mas outras..$^{50}$ Logo, trata-se de saber em que a espécie do enigma difere do gênero da alegoria.

${ }^{46}$ Cic. De or. 3.42.167: etenim hoc fere genere fiunt ea, quae dicuntur aenigmata.

${ }^{47}$ Quint. 8.6.14: Vt modicus autem atque oportunus eius usus inlustrat orationem [...] continuus uero in allegorian et aenigmata exit.

${ }^{48}$ J. VicT. Ars rhet. 20: RLM p. 432, 1. 19-20: etenim ex hoc fere genere fiunt ea, quae dicuntur aenigmata.

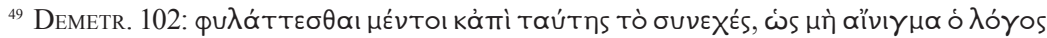

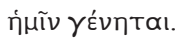

${ }^{50} \mathrm{Na}$ verdade, dos gregos um único dá enigma como espécie de alegoria: Cocôndrio (Cocondr.: $A G$ Boiss. III p. 295, 1. 21-2). Entre os latinos, os que arrolam enigma entre as espécies de alegoria são gramáticos dos séc. III-IV d.C., a saber: Mário Plócio Sacerdote (SACERD. Art. gram.: GL VI p. 461, 1. 10-2), Carísio (ChAR. Ars gram.: GL I p. 276, 1. 7-8), Diomedes (Diom. Ars gram.: GL I p. 462, 1. 5-6) e Donato (Don. $A M$ : GL IV p. 401, 1. 28-30), e os demais são gramáticos que dependem desses, a saber: Pompeio (Pomp. Com. art. Don.: GL V p. 311, 1. 10-2), Isidoro de Sevilha (Isid. Orig. 1.37.22), Juliano de Toledo (Iulian. Tol. Ars 19.86-91), Livro I dos vícios e virtudes da oração (I Vit. uirt. or. 669-91), Livro II dos vícios e virtudes da oração (II Vit. uirt. or. 392-4), Beda o Venerável (BED. De fig. et trop.: RLM p. 615, 1. 34-5), Murethach de Irlanda (Мrтнсн. In Don. AM: CCCM XL p. 247, 1.34 - p. 248, 1. 41), Arte de Lorsh (Ars Laur.: CCCM XLa p. 234, 1. 63-7), Sedúlio de Escócia (SEdul. In Don. AM: CCCM XLb p. 386, 1. 8-10), Comentário de Einsiedeln ao Barbarismo de Donato (Com. Einsidl. in Don. barb.: GL Supl. p. 272, 1. 35 - p. 273, 1. 7), Mateus de Vendôme (Mat. Vin. $A V$ 3,43-4), Alexandro de Villedieu (Alex. V.-D. Doctr. 2542-5), Gervásio de Melkley (Gerv. AP p. 149, 1. 8-9). 
Ora, nem Demétrio nem Cícero ou Quintiliano ou Caio Júlio Vítor elucidam o que seja a continuação da alegoria; demais, se se aplica a esta a razão que aqueles aplicam à continuação da metáfora, incorre-se em impasse. Pois, se a continuação da metáfora é uma sequência de palavras metafóricas que preenche toda a oração, a continuação da alegoria seria uma sequência de orações alegóricas que preenchesse todo o arrazoado; ou ainda, se a alegoria se faz no todo da oração, o enigma se faria no todo do arrazoado. No entanto, obstam a tal conclusão os exemplos com que aqueles mesmos rétores ilustram a alegoria e o enigma. De fato, o primeiro exemplo de alegoria dado por Quintiliano é uma ode inteira de Horácio, de maneira que assinale uma série de metáforas que preenche, não uma tira da ode, mas todo o corpo do poema (Quint. 8.6.44: Hor. O. 1.14; cf. totusque ille Horati locus); já o exemplo de enigma que nos depara consta de uma única oração de uma écloga de Vergílio (Quint. 8.6.52: VERG. B. 3.104-5).

O mesmo Quintiliano, porém, observa que o que se diz enigma é a alegoria que é mais obscura, mas não explica sobre que incide a obscuridade de tal alegoria. O mais dos que arrolam o enigma entre as espécies de alegoria diz tão-só que o enigma é alegoria obscura ou difícil, de maneira que, como Quintiliano, também não explicam sobre que recai a dificuldade ou obscuridade de tal alegoria, e Pompeio observa que o enigma é questiúncula que ninguém entende, ${ }^{51}$ mas não explica por quê. Isidoro de Sevilha, porém, e, na esteira deste, Juliano de Toledo, sobre dizer, como Pompeio, que o enigma dificilmente se entende se não é desvendado, ${ }^{52}$ distinguem entre alegoria e enigma. Assim, dizem que alegoria e enigma diferem nisto de a alegoria ser um valor geminado e indicar um caso sob outros casos, e o enigma, um sentido obscuro e ter obscura intelecção na sentença. ${ }^{53}$ Ora, se a alegoria é valor geminado porque sobrepõe um caso a outro, ou ainda, o caso que se entende pela dicção ao caso que se subentende pela intelecção, o enigma sobreporia um caso que não se entende a um caso que dificilmente se subentende. Isso, porém, equivaleria a dizer

\footnotetext{
${ }^{51}$ Poмp. Com. art. Don.: GL V p. 311, 1. 6-7: quaestiunculas, quas nullus intellegit.

${ }^{52}$ IsID. Orig. 1.37.26: qui difficile intellegitur nisi aperiatur; Iulian. Tol. Ars 19.87: qui difficile intellegitur nisi aperiatur.

${ }^{53}$ IsID. Orig. 1.37.26: Inter allegoriam autem et aenigma hoc interest, quod allegoria vis gemina est et sub res alias aliud figuraliter indicat; aenigma vero sensus tantum obscurus est, et per quasdam imagines adumbratus; Iulian. Tol. Ars 19.89-91: Inter allegoriam autem et aenigma hoc interest, quod allegoria uis gemina est et sub res alias aliud figuraliter indicat. [...] Aenigma uero est sensus obscurus et per quasdam imagines adumbratus, habens aut in sententia obscurum intellectum aut per similitudines alium sensum.
} 
que do enigma o caso próprio não tem valor, de maneira que o enigma não seja valor geminado, mas valor simples. Daí, reparo naquele comentário de João de Sicília a este passo de Gregório de Nazianzo: “existe, pela fábula, tufo que cresce quando cortado" (NAz. In seipsum cum rure red. 26.10: $P G$ XXXV 1240, 42-3), o qual aduz como exemplo de alegoria. Ora, o Rétor contesta aqueles que, ao explicar as palavras do Teólogo, dizem que são referidas a cabelos ou vide ou loureiro ou outros tais, porque, como diz, esses e outros tais são casos verdadeiros, e não fábulas, que são arrazoado falso que se assemelha à verdade, ou melhor, arrazoado cujo caso não existe segundo a verdade e, portanto, nada significa por si mesmo. ${ }^{54}$ Assim, ao recusar significado ao caso próprio e admitir apenas a intelecção do caso alheio, João estaria a tratar o dito de Gregório de Nazianzo, não bem como alegoria, mas como enigma. Daí, reparo que não por acaso o comentário de João de Sicília é encabeçado pela definição de alegoria como arrazoado que enigmatiza um entendimento por meio de outros..$^{55}$ Seja como for, teria sido mais exato se tivesse concluído, a seguir, que a fábula é arrazoado que enigmatiza o entendimento de um caso por meio de caso que não se entende.

TITRE. La définition d'allégorie chez les grammairiens et rhéteurs grecs et latins.

Résumé. La définition d'allégorie la plus fréquente chez les grammairiens et rhéteurs, aussi bien grecs que latins, est que l'allégorie dit une chose et comprend une autre. Aussi, j'examine d'abord les grammairiens et rhéteurs qui s'occupent de distinguer ce qui se dit et ce qui se comprend, ou à expliquer comment l'allégorie fonctionne au niveau de la diction, c'est à dire, des mots, et comment elle fonctionne au niveau de la compréhension, c'est à dire, des concepts. Une autre description d'allégorie, rare chez les grammairiens et rhéteurs, est que l'allégorie transfère les mots du concept propre à l'autre concept, ce qui fait penser à la définition de métaphore. Aussi, j'examine ensuite les grammairiens et rhéteurs qui enseignent, par exemple, en quoi l'allégorie se distingue de la métaphore.

Mots-CLEFS. Allégorie; métaphore; énigme; trope.

${ }^{54}$ IoH. Sicul. Enar. spec. Hermog. I 6,25: $R G$ VI 221,15-22: Пра̃ $\gamma \mu \alpha \mu \varepsilon ́ v т о$ ката̀

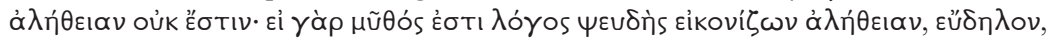

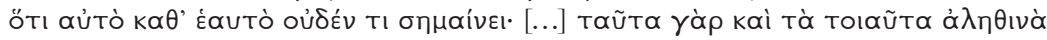

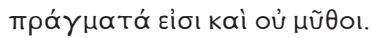

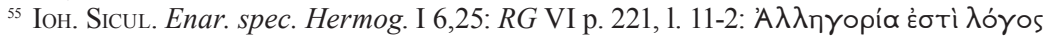

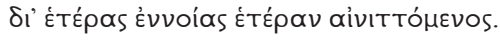

